\title{
ESTIMATIVA DE CENÁRIOS CARACTERÍSTICOS DE ONDAS NA ENSEADA DE SÃO LOURENÇO DO SUL, LAGOA DOS PATOS - RS
}

\author{
Natália Lemke $e^{1}$,José Antônio Scotti Fontoura ${ }^{2}$, Lauro Julio Calliari ${ }^{1}$ \& Nicole Motta Ferreira ${ }^{{ }^{*}}$
}

\section{RESUMO}

LEMKE, N.; FONTOURA, J.A.S.; CALLIARI, L.J.; FERREIRA, N.M. Estimativa de cenários característicos de ondas na ensedada de São Lourenço do Sul, Lagoa dos Patos - RS. Perspectivas Online: Exatas \& Engenharias, v. 8, n.20, p.25-42,2018.

Este trabalho visa determinar cenários característicos de ondas na Lagoa dos Patos, nas proximidades da enseada de São Lourenço do Sul. Utilizou-se o modelo SWAN, o qual foi aferido com dados de ondas medidos na Lagoa dos Patos, em março de 2015, através de um ondógrafo direcional fundeado a aproximadamente $14 \mathrm{~km}$ da costa de São Lourenço do Sul, no ponto de coordenadas $31^{\circ} 29^{\prime} 06^{\prime}$ 'S e $51^{\circ} 55^{\prime} 07^{\prime}$ ' $\mathrm{W}$, onde a profundidade local é de seis metros. A partir do modelo SWAN foram obtidos os parâmetros de ondas (alturas significativas, períodos de pico e direções de pico) para todo ano de 2008 (ano representativo de ventos) a cerca de $5 \mathrm{~km}$ da enseada de São Lourenço do Sul. Posteriormente, selecionaram-se 36 cenários característicos de ondas com valores de alturas significativas (Hs) entre $0,16 \mathrm{~m}$ e $1,03 \mathrm{~m}$, com períodos de pico (Tp) entre 2,05 s e 4,54 s, e com direções de pico (Dp) entre $30^{\circ}$ e $210^{\circ}$. A estimativa destes cenários de ondas tem importante contribuição com estudos que visam caracterizar o regime de ondas na laguna e até mesmo quantificar o transporte sedimentar na enseada de São Lourenço do Sul, para então propor obras de proteção costeira na região.

Palavras-chave: Ondas na Lagoa dos Patos; Ondógrafo Direcional; SWAN. 


\begin{abstract}
This work aims to determine characteristic wave sceneries in the Lagoa dos Patos, nearby the São Lourenço do Sul embayment. The SWAN model was used, and it was honed with wave data which were measured in the Lagoa dos Patos, in March 2015, through a waverider buoy moored about 14 $\mathrm{km}$ from the São Lourenço do Sul coast, at coordinates $31^{\circ} 29^{\prime} 06$ "S and $51^{\circ} 55^{\prime} 07^{\prime} \mathrm{W}$, with local depth of six meters. Wave parameters (significant heights, peak periods and peak directions) were obtained from the SWAN model for the whole year 2008 (winds representative

year) about $5 \mathrm{~km}$ from the São Lourenço do Sul embayment. Subsequently, 36 characteristic wave sceneries were selected with significant height (Hs) between $0.16 \mathrm{~m}$ and $1.03 \mathrm{~m}$, peak periods (Tp) between $2.05 \mathrm{~s}$ and $4.54 \mathrm{~s}$, and peak directions (Dp) between $30^{\circ}$ and $210^{\circ}$. The estimate of these wave sceneries has important contribution to studies which aim to characterize the wave climate in the lagoon and even quantify the sedimentary transport in the São Lourenço do Sul embayment, in order to propose coastal protection actions in the area.
\end{abstract}

Keywords: Waves in Patos Lagoon; Waverider Buoy; SWAN.

\footnotetext{
${ }^{1}$ Universidade Federal do Rio Grande, FURG - Instituto de Oceanografia,Campus Carreiros, Avenida Itália, Km 8, s/n Carreiros, Rio Grande, RS, CEP: 96201-900,Brasil

${ }^{2}$ Universidade Federal do Rio Grande do Sul, UFRGS - Av. Paulo Gama, 110, Farroupilha, Porto Alegre , RS, 90040060, Brasil.

(*)e-mail: nicole.ferreiraa@hotmail.com

Data de chegada: 07/05/2017 Aceito para publicação: 29/05/2017
}

Persp. Online: exatas \& eng., Campos dos Goytacazes, 20 (08) 25-42 - 2018 


\section{INTRODUÇÃO}

A caracterização do regime de ondas em ambientes litorâneos apresenta extrema importância para profissionais da oceanografia e da engenharia oceânica, pois as estruturas de proteção costeira, como quebramares e espigões, são projetadas de acordo com o padrão de ondas incidentes. As ondas são as principais responsáveis pelo transporte de sedimentos dentro da zona de arrebentação. Após o processo de quebra da onda, os fluxos de sedimentos são regidos pelas quantidades de movimento introduzidas dentro da zona de surfe (FONTOURA, 2004). De acordo com Machado (2013) o regime de ondas de uma região depende do clima, da localização de sistemas atmosféricos e dos ventos predominantes, e é caracterizado através do padrão estatístico de altura, período, direção de propagação e energia.

A Lagoa dos Patos (Figura 1) é uma grande laguna costeira localizada no extremo sul do Brasil. É integrante principal do sistema de drenagem da bacia hidrográfica do sudeste. Possui orientação geral NE-SW, comprimento médio de $250 \mathrm{~km}$ e largura média de $40 \mathrm{~km}$, cobrindo uma área de aproximadamente $10.000 \mathrm{~km}^{2}$ (FONTOURA et al., 2015). Embora seja o principal corpo hídrico da Hidrovia do MERCOSUL, até o ano de 2015 não havia conhecimento de estudos detalhados do seu regime ondulatório. As primeiras predições de ondas nas margens oeste e leste da Lagoa dos Patos foram feitas por Toldo et al. (2006) com base em dados horários de ventos medidos durante o ano de 1988. Em março de 2004, Fischer e Calliari (2011) realizaram medições de alturas de ondas utilizando uma régua graduada nas praias do "Saco do Laranjal" (costa noroeste do estuário da Lagoa dos Patos). Nicolodi (2013) validou um modelo de geração de ondas para o Lago Guaíba (norte da Lagoa dos Patos) através da aferição com dados obtidos por um medidor de ondas e correntes da FSI3D da Falmouth Scientific, fundeado entre os dias 16 de junho até 02 de agosto de 2005, em uma profundidade aproximada de três metros.

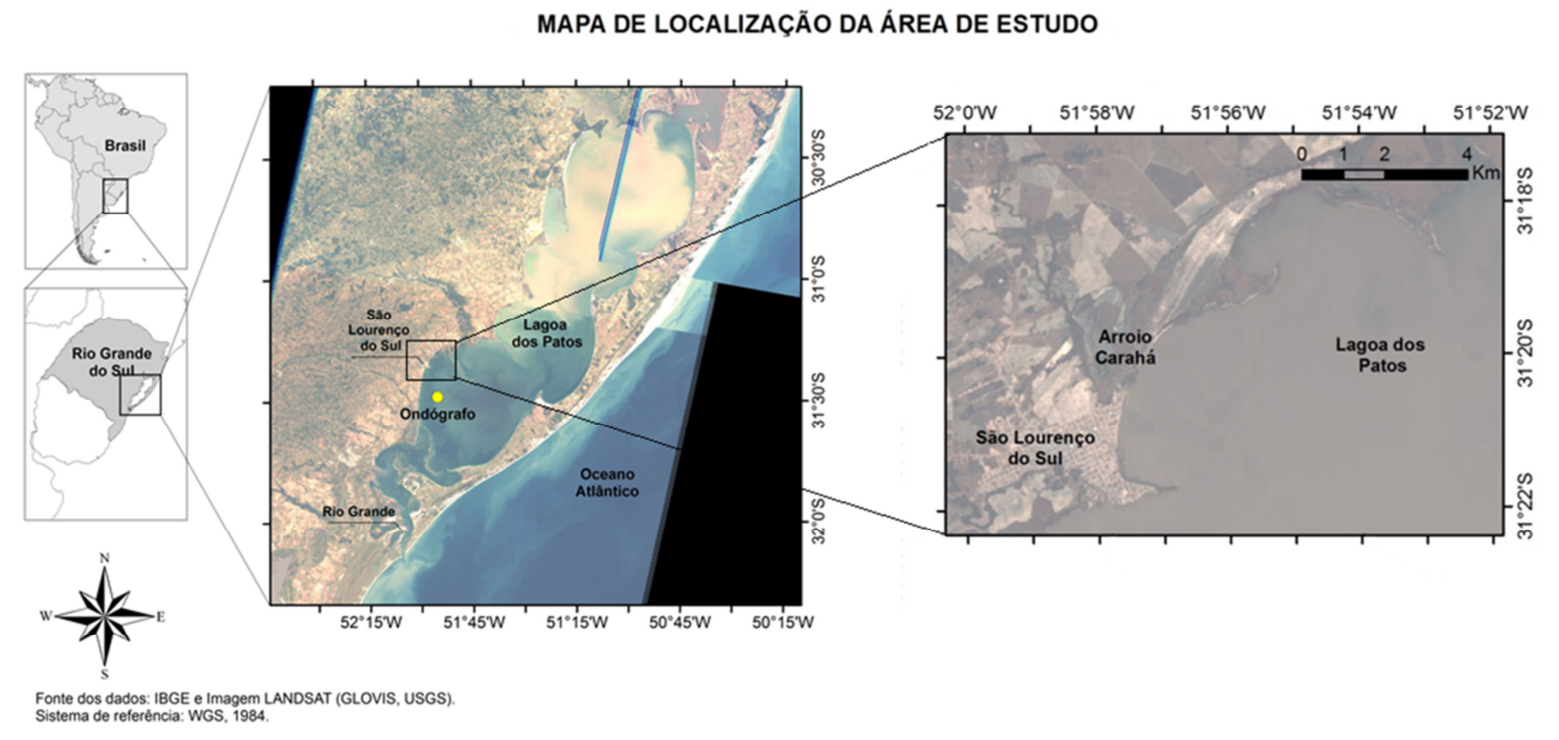

Figura 1: Mapa de localização da área de estudo e localização do ondógrafo na Lagoa dos Patos - RS

Além da medição dos parâmetros de ondas in situ, o regime ondulatório em uma região também pode ser estimado através da modelagem computacional, uma vez feita a aferição do modelo com dados observados. O modelo SWAN (Simulating Waves Nearshore) é uma ferramenta de extrema valia para simular a geração e propagação de ondas em águas rasas. Diversos pesquisadores têm utilizado o SWAN para modelagem de ondas em ambientes abrigados, como por exemplo, Lago George na Austrália (Van Gruijthuijsen, 1996), Baía de Chesapeake nos Estados Unidos (Lin et al., 2002), Lago Erie (Moeini e Shahidi, 2009) e Lago Guaíba (Nicolodi, 2007). 
Desta forma, este estudo tem o propósito de identificar cenários característicos de ondas na Lagoa dos Patos, a cerca de $5 \mathrm{~km}$ da enseada de São Lourenço do Sul (Figura 1), através do modelo SWAN, aferido com dados de ondas medidos por meio de um ondógrafo direcional. Os resultados adquiridos com esta pesquisa auxiliam na caracterização do regime ondulatório lagunar, dando origem a uma consistente base para outros estudos que visam determinar o transporte sedimentar na região, e assim, propor obras de fixação e proteção da costa.

\section{METODOLOGIA}

A metodologia desenvolvida nesta pesquisa consiste na aquisição e tratamento dos dados de batimetria, de ondas e de ventos, assim como na modelagem computacional, à qual foi realizada através do SWAN. A seguir são detalhadas estas etapas.

\subsection{Levantamento batimétrico}

Dados batimétricos da Lagoa dos Patos foram adquiridos através de cartas náuticas, disponibilizadas no site Diretoria de Hidrografia e Navegação (DHN). Através do software DELFT3D construiu-se uma grade numérica retangular (grade regional), rotacionada a $30^{\circ}$ no sentido horário a partir do eixo norte, com 108.741 nós espaçados a cada 500 metros. A grade regional e os pontos batimétricos digitalizados a partir das cartas náuticas são apresentados nas Figuras 2 e 3, respectivamente.

Na enseada de São Lourenço do Sul, realizou-se um levantamento batimétrico detalhado no dia 18 de outubro de 2013, com uma ecossonda da marca Lowrance $C$ (modelo LCX-19C) de dupla frequência 200/50 kHz e com precisão vertical da ordem de centímetros. Através do software DELFT3D construiu-se uma grade numérica retangular (grade local), rotacionada a $30^{\circ}$ no sentido horário a partir do eixo norte, composta por 58.056 nós. As Figuras 4 e 5 ilustram, respectivamente, a grade local e as linhas de navegação com os perfis batimétricos obtidos.

Após o tratamento dos dados batimétricos realizou-se a interpolação triangular através do software DELFT3D para ambas as grades numéricas. 


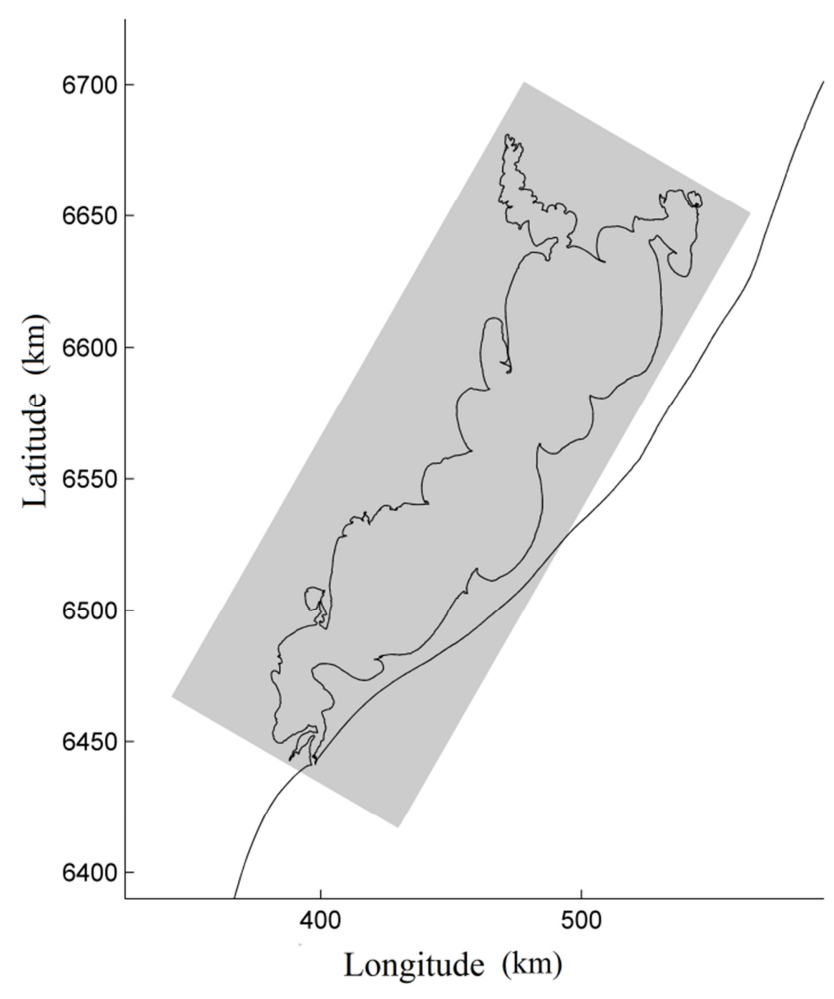

Figura 2: Grade numérica para a Lagoa dos Patos (coordenadas métricas UTM)

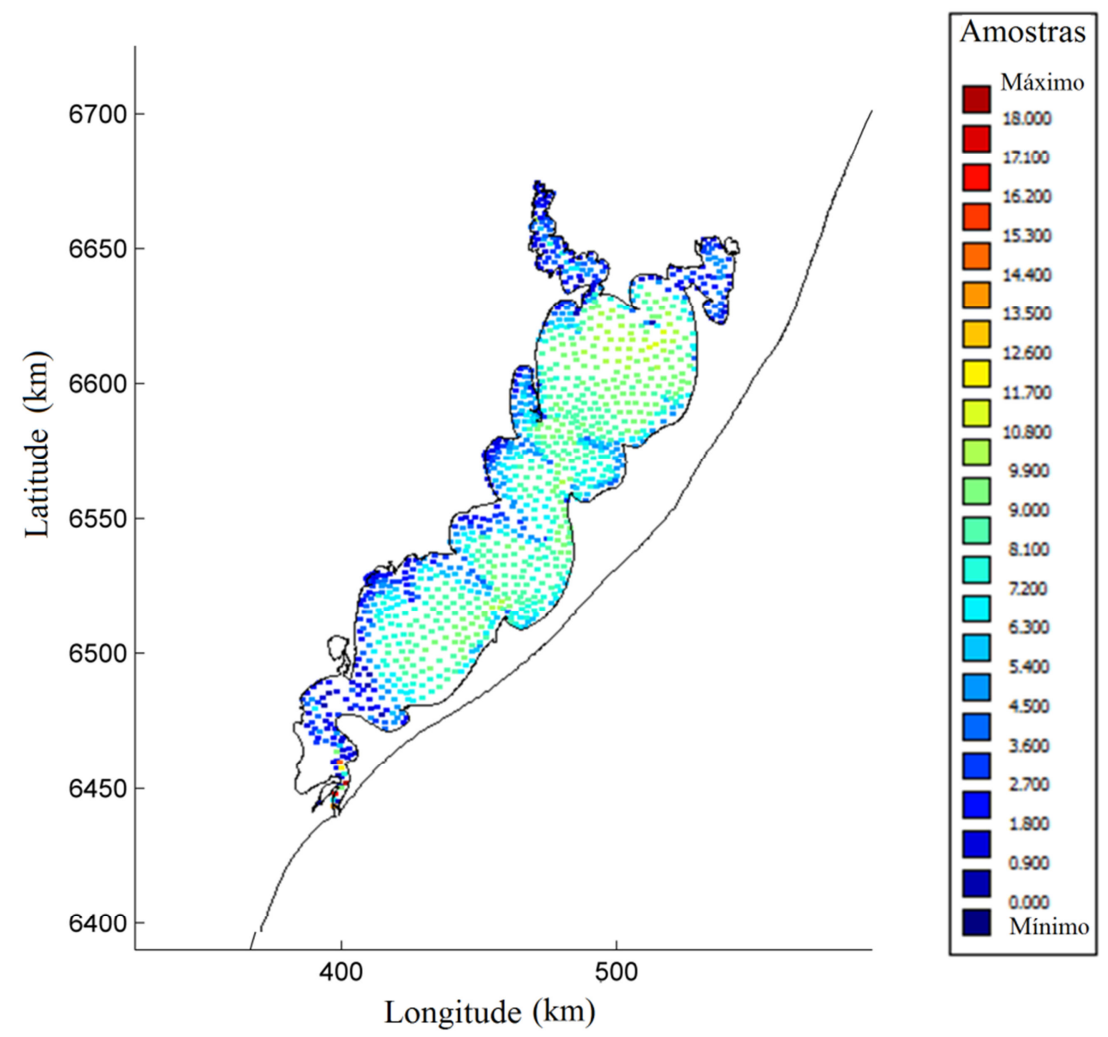

Figura 3: Pontos batimétricos da Lagoa dos Patos (coordenadas métricas UTM e escala de cores em metros)

Persp. Online: exatas \& eng., Campos dos Goytacazes, 20 (08) 25-42 - 2018 seer.perspectivasonline.com.br 


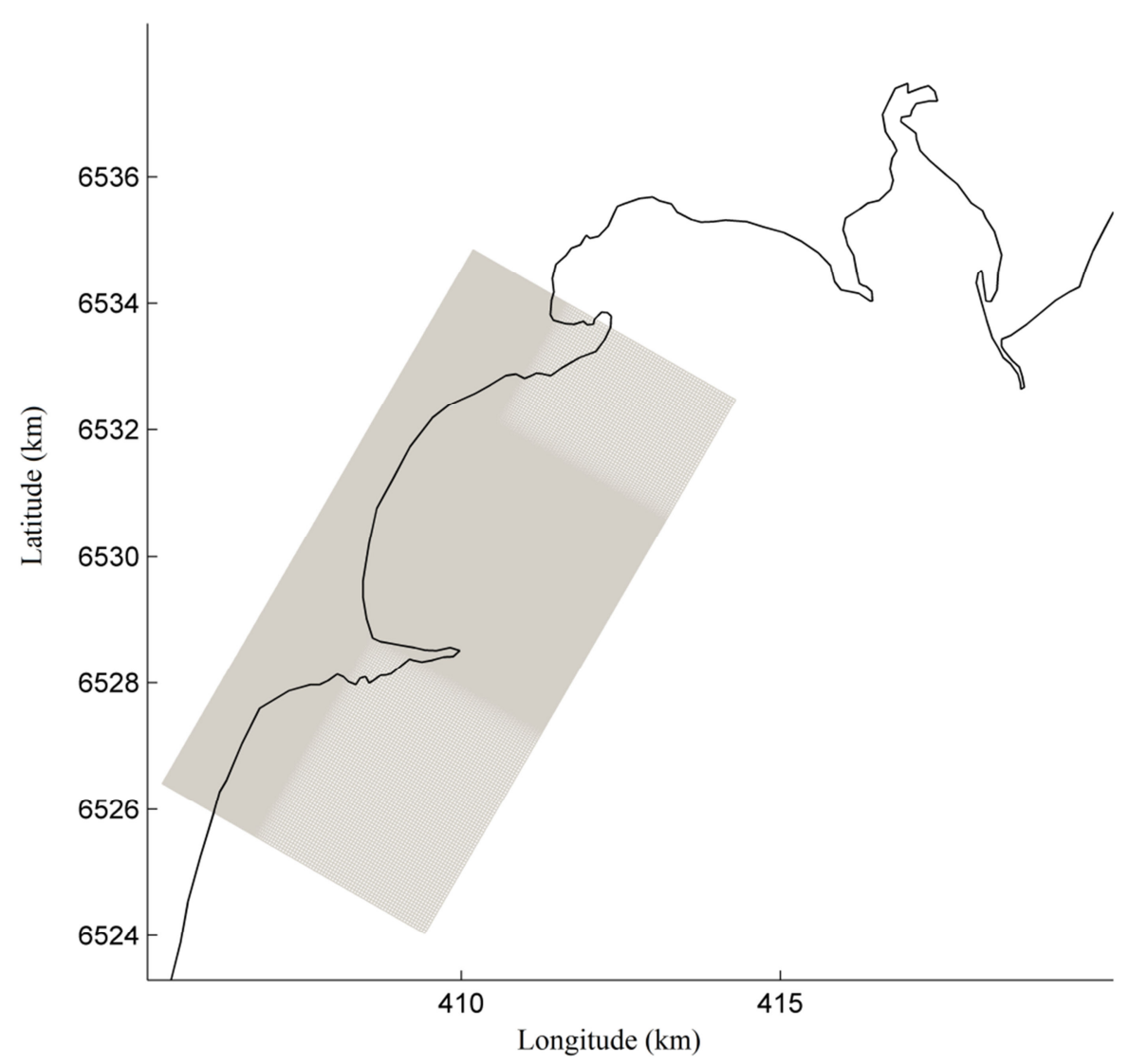

Figura 4: Grade numérica para a enseada de São Lourenço do Sul (coordenadas métricas UTM)

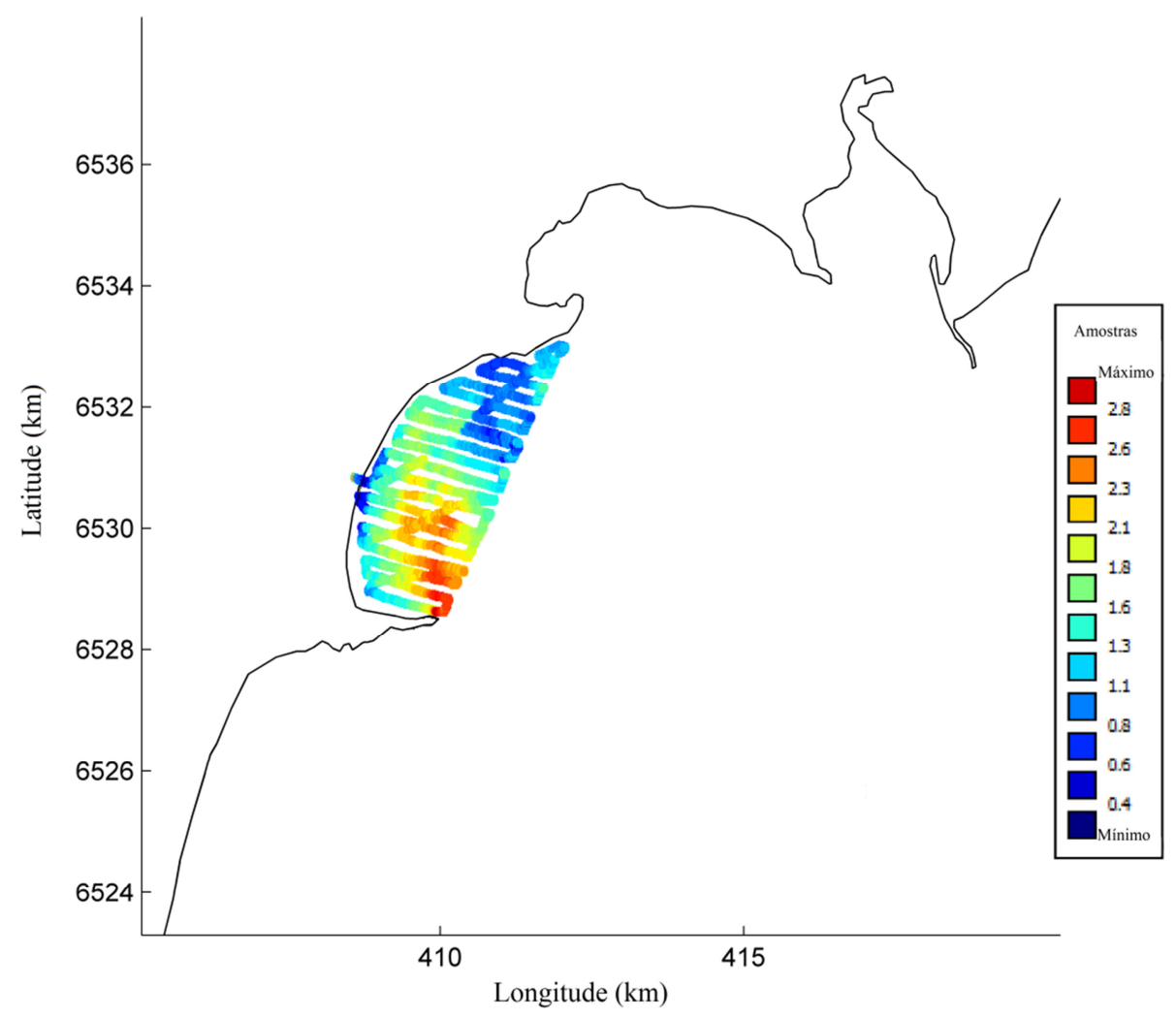

Figura 5: Transectos durante o levantamento batimétrico detalhado para a enseada de São Lourenço do Sul (coordenadas métricas UTM e escala de cores em metros)

Persp. Online: exatas \& eng., Campos dos Goytacazes, 20 (08) 25-42 - 2018 seer.perspectivasonline.com.br 


\subsection{Parâmetros de ondas medidos na Lagoa dos Patos}

Registros inéditos de parâmetros de ondas na Lagoa dos Patos foram adquiridos através do ondógrafo direcional Waverider Datawell Mark III fundeado a uma distância de aproximadamente $14 \mathrm{~km}$ da costa de São Lourenço do Sul, no ponto de coordenadas $31^{\circ} 29^{\prime} \mathrm{S}$ e $51^{\circ} 55^{\prime} \mathrm{W}$ (Figura 1), onde a profundidade local é de 6 metros. O ondógrafo pertence à FURG, via projeto Rede Ondas (Rede de Monitoramento de Ondas em Águas Rasas) da Comissão Interministerial para os Recursos do Mar.

Registros de altura, período e direção de onda, temperatura da água e a posição geográfica foram adquiridos durante o intervalo temporal de 22 de janeiro a 01 de julho de 2015 . Para a aferição do modelo SWAN foram utilizados os dados de ondas referentes a março de 2015. Através de uma antena de rádio, posicionada no topo do ondógrafo, foi realizada a transmissão dos dados brutos e espectrais para a estação receptora localizada na FURG - Campus São Lourenço do Sul e, então, via internet para a FURG - Rio Grande. Parâmetros de ondas (altura significativa, período de pico e direção de pico), foram divulgados em tempo real no site redeondas.herokuapp.com. Informações mais detalhadas sobre a aquisição, instalação e operação do ondógrafo podem ser encontrados nos estudos de Fontoura et al. (2015) e de Lemke (2015).

\subsection{Análise de dados de ventos}

Para simular a geração de ondas na Lagoa dos Patos é fundamental o conhecimento do regime de ventos atuantes na região. Desta forma, dados horários de ventos medidos na estação meteorológica da Praticagem da Barra do Rio Grande, coletados a 25 metros de altura, foram convertidos para dados correspondentes a 10 metros de altura (altura de referência no SWAN), de acordo com a Equação 1 (U. S. ARMY CORPS OF ENGINEERS, 1984), onde $z$ é a altura em que foram feitas as medições $(25 \mathrm{~m})$, e $u_{z}$ é a intensidade da velocidade do vento na altura $z$.

A série histórica de dados de ventos da Praticagem compreende o período de 2004 a 2010 . Com intuito de reduzir o esforço computacional, aplicou-se a metodologia apresentada por Romeu et al. (2010), onde 30 anos de dados de agitação marítima da região oceânica sul brasileira foram reconstruídos, através do modelo de geração WW3, e histogramas de altura e período de ondas por direção de incidência destes 30 anos foram comparados com histogramas anuais, com a finalidade de identificar o ano que melhor representava a totalidade de dados. Desta forma, os valores de velocidades de ventos coletados na Praticagem da Barra do Rio Grande foram divididos em classes (intervalos de $3 \mathrm{~m} / \mathrm{s}$ ), com intuito de determinar a distribuição de frequências (\%) de acordo com as direções predominantes para todo período analisado (2004 a 2010), assim como para cada ano separadamente. Construíram-se matrizes com os valores de desvio padrão das frequências relativas de velocidades de ventos, conforme direções atuantes, tendo como valores médios as frequências para todo período analisado (2004 a 2010). Após obter os valores de desvio padrão das frequências relativas de cada ano, calculou-se o desvio padrão médio anual. $\mathrm{O}$ ano que apresentou o menor desvio padrão anual foi selecionado como ano representativo de toda série temporal (2004 a 2010). Especificamente para a aferição do modelo SWAN, utilizou-se a série temporal de dados de ventos referentes a março de 2015 .

Análises sobre a variação espacial do vento sobre a extensa área da Lagoa dos Patos foram feitas através da correlação linear entre dados de ventos da Praticagem e dados de ventos do modelo de reanálise europeu ECMWF. Informações mais detalhadas encontram-se no estudo de Lemke (2015).

Persp. Online: exatas \& eng., Campos dos Goytacazes, 20 (08) 25-42 - 2018 


\subsection{Geração de ondas na Lagoa dos Patos através do modelo SWAN}

O modelo SWAN foi aferido a partir da comparação estatística entre dados de ondas modelados e dados de ondas medidos através do ondógrafo durante março de 2015. As séries temporais de altura significativa, período de pico e direção de pico, tanto medidas quanto modeladas, durante o mês de março de 2015, foram analisadas com base nos cálculos estatísticos disponíveis na literatura (MELO et al., 2008, LALBEHARRY, 2001, AGUIAR, 2014). Informações mais detalhadas encontram-se no trabalho desenvolvido por Lemke et al. (2015).

Após realizar a aferição do modelo SWAN e determinar o ano representativo de ventos da série temporal de 2004 a 2010, simulou-se a geração e a propagação de ondas em toda a Lagoa dos Patos, com a grade numérica regional, obtendo-se parâmetros de ondas (alturas significativas, períodos de pico e direções de pico) em pontos situados na fronteira da grade local (São Lourenço do Sul) em intervalos de 3 horas, totalizando 2928 casos durante um ano inteiro. Por conseguinte, aplicou-se a metodologia desenvolvida por Dobrochinski (2009), à qual consiste na redução do clima de ondas. A metodologia denomina-se Método das Classes Fixadas, onde os casos de ondas da série temporal são divididos em classes de direção e de altura significativa. As classes de direção têm o mesmo tamanho. Cada classe de direção é dividida em classes de altura significativa, de acordo com a altura significativa máxima encontrada dentro da classe direcional. $\mathrm{O}$ tamanho das classes de altura significativa é o mesmo dentro de cada classe de direção, mas pode variar nas outras classes direcionais. O número total de casos de ondas é adquirido através da multiplicação do número de classes de direção pelo número de classes de altura significativa de onda. $\mathrm{O}$ valor do período de pico de cada classe é determinado através da média aritmética dentro da referida classe.

Portanto, dividiu-se a série temporal dos casos de ondas obtidos com a modelagem em quatro intervalos, um para cada estação do ano. Após, aplicou-se o Método das Classes Fixadas para cada estação do ano. Devido às feições morfológicas da região no entorno da grade local (conforme se observa nas Figuras 4 e 5) constata-se que as maiores pistas de vento ocorrem entre $30^{\circ}$ e $210^{\circ}$. Desta forma, analisaramse resultados dos parâmetros de ondas gerados pelo SWAN para todo ano representativo, com direções de pico entre $30^{\circ}$ e $210^{\circ}$. Os demais casos de ondas não foram utilizados, visto que não haveria pista de vento suficiente para gerar ondas. As classes de direção de pico das ondas foram dividas em 3 partes iguais, com $60^{\circ} \mathrm{em}$ cada classe. Dentro de cada classe direcional, fez-se a divisão de altura significativa em 3 partes. Assim, foram selecionados 9 casos de ondas representativos para cada estação do ano, totalizando 36 cenários de ondas característicos da região de estudo.

\section{RESULTADOS E DISCUSSÃO}

\subsection{Interpolação de dados batimétricos}

As Figuras 6 e 7 apresentam, respectivamente, as batimetrias da Lagoa dos Patos e da enseada de São Lourenço do Sul resultantes da metodologia de interpolação triangular de dados de profundidades, realizada através do software DELFT3D. Observa-se que a profundidade média da Lagoa dos Patos é da ordem de 6 metros. Já nas proximidades de São Lourenço do Sul, a batimetria é mais rasa, apresentando valores máximos menores que 3 metros.

Na Figura 7 também podem ser observados os pontos (A, B, C e D) onde foram analisados os parâmetros de ondas resultantes da modelagem de ondas na Lagoa dos Patos (grade regional). Dentre os quatro pontos, o que possui maior profundidade é o ponto $\mathrm{A}$, com o valor de 2,8 metros.

Persp. Online: exatas \& eng., Campos dos Goytacazes, 20 (08) 25-42 - 2018 

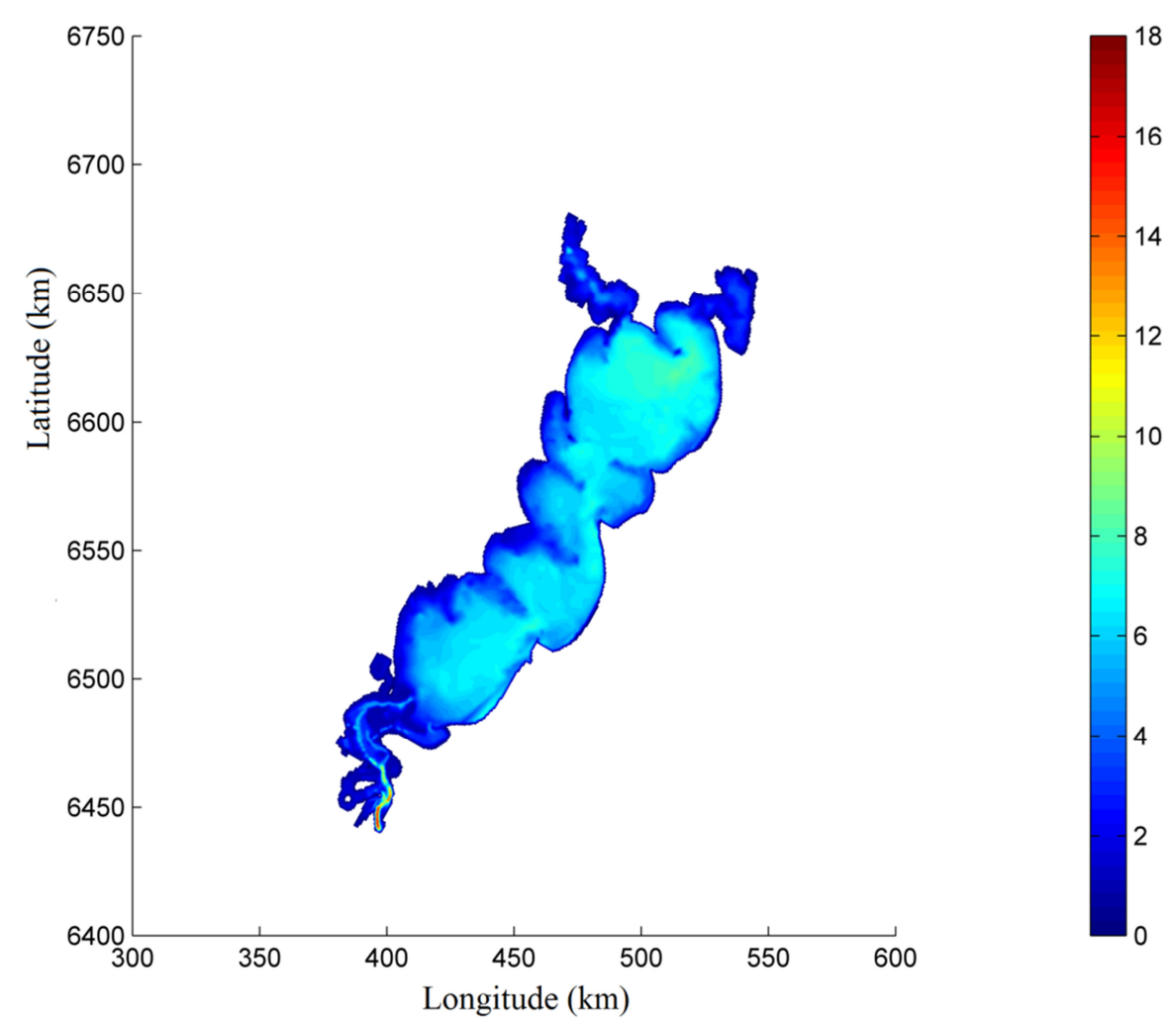

Figura 6: Batimetria da Lagoa dos Patos resultante da interpolação de dados de profundidades (coordenadas métricas UTM e escala de cores em metros)

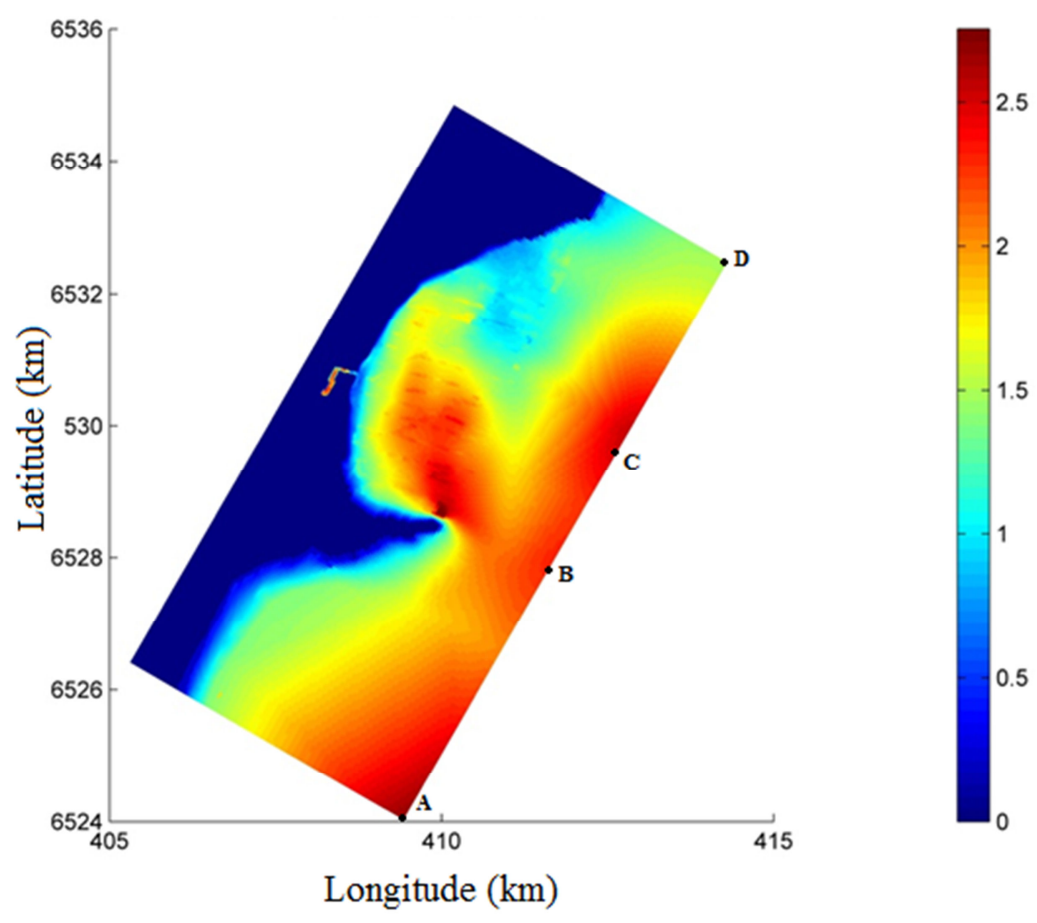

Figura 7: Batimetria da enseada de São Lourenço do Sul resultante da interpolação de dados de profundidades e localização dos pontos (A, B, C e D) onde se analisaram os resultados dos parâmetros de ondas gerados através da modelagem (coordenadas métricas UTM e escala de cores em metros)

Persp. Online: exatas \& eng., Campos dos Goytacazes, 20 (08) 25-42 - 2018 seer.perspectivasonline.com.br 


\subsection{Parâmetros de ondas medidos na Lagoa dos Patos}

Na Figura 8 são apresentadas as rosas de ondas para alturas significativas e para períodos de pico, de acordo com as direções de pico, a partir dos parâmetros de ondas adquiridos com o ondógrafo direcional fundeado na Lagoa dos Patos. São apresentados somente os resultados referentes a março de 2015, período adotado para a aferição do modelo SWAN. Durante março de 2015, ondas com direções de pico de leste ocorreram com maiores frequências $(51,6 \%)$. Em relação à altura significativa, as maiores frequências corresponderam a ondas de 0,3 a 0,6 metros $(19,9 \%)$, de 0,6 a 0,9 metros $(17 \%)$ e de até 0,3 metros $(9,55 \%)$, ambas com direção de pico de leste. Ondas com períodos de pico entre 3 e 3,5 segundos e direções de pico de leste incidiram com maiores frequências $(16,3 \%)$, seguidas de ondas com períodos de pico entre 3,5 e 4 segundos (13,1\%), entre 2,5 e 3 segundos $(9,87 \%)$ e entre 4 e 4,5 segundos $(7,28 \%)$, ambas com direções de pico de leste.

Os parâmetros de ondas adquiridos através do ondógrafo podem ser comparados com os resultados obtidos por Toldo et al. (2006) no estudo de predição de ondas na Lagoa dos Patos. Os valores médios de altura significativa $(0,6$ metros) e período (3,1 segundos) das ondas obtidos por Toldo et al. (2006) para o verão são muito semelhantes aos parâmetros de ondas adquiridos pelo ondógrafo em março de 2015 (período específico deste estudo), os quais foram, respectivamente, 0,57 metros para altura significativa e 3,33 segundos para período de pico. Quanto às direções das ondas, Toldo et al. (2006) estabeleceram às mesmas direções dos ventos atuantes na região. No entanto, Lemke (2015) verificou a correlação linear entre dados de direções de ventos medidos na Estação Meteorológica da Praticagem da Barra do Rio Grande e dados de direções de pico das ondas, obtidos pelo ondógrafo, constatando a ocorrência da refração das ondas na Lagoa dos Patos. Embora a localização do ponto de comparação entre os parâmetros de ondas obtidos por Toldo et al. (2006) não seja exatamente o mesmo local de fundeio do ondógrafo, os resultados encontrados pelas diferentes metodologias para alturas significativas e períodos são muito semelhantes.
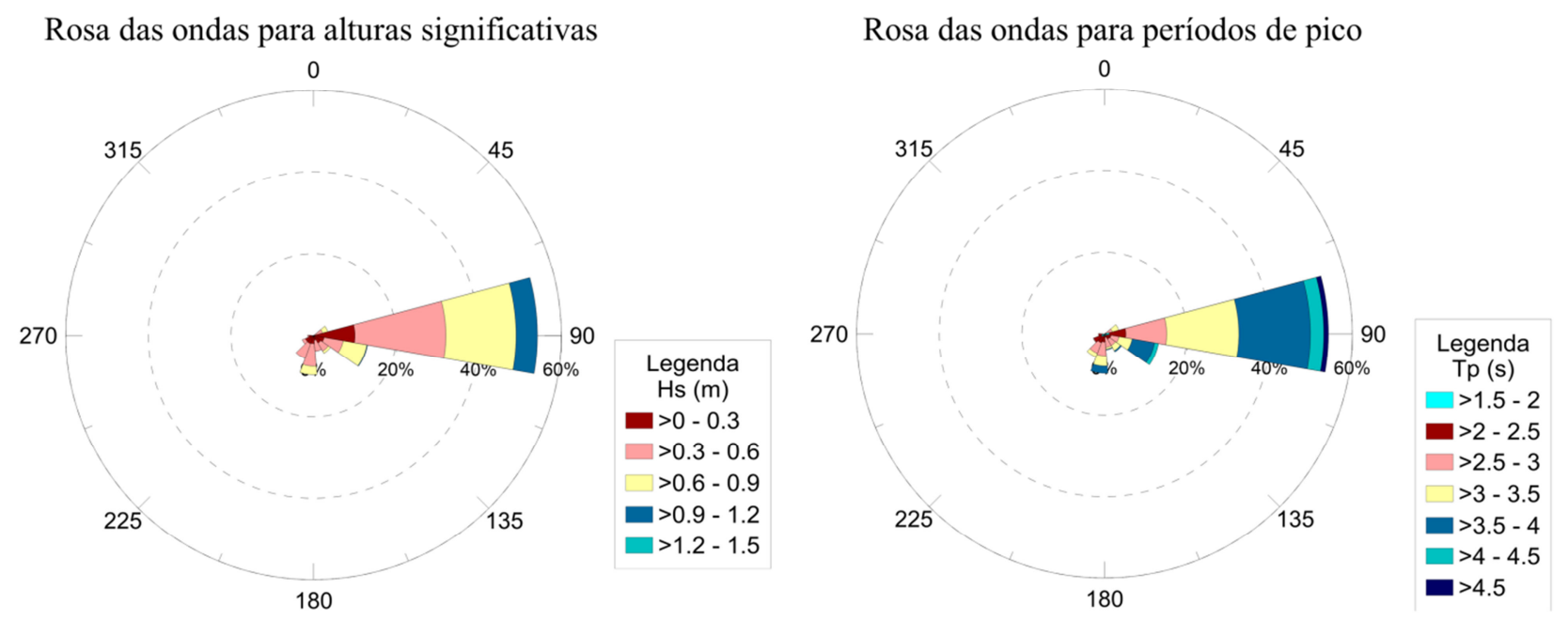

Figura 8: Rosas das ondas para alturas significativas (esquerda) e para períodos de pico (direita) conforme as direções de pico, de acordo com os dados medidos através do ondógrafo direcional durante março de 2015

\subsection{Análise de dados de ventos}

Na Tabela 1 são apresentados os resultados de desvio padrão médio anual, os quais foram calculados de acordo com as frequências de ocorrências das classes de ventos (intervalos de $3 \mathrm{~m} / \mathrm{s}$ ) para cada ano (2004 a 2010). Verifica-se que o menor desvio padrão é referente ao ano de 2008. Portanto, os dados de velocidades e direções de ventos que melhor representam todo período estudado (2004 a 2010) são referentes ao ano de 2008, o qual foi selecionado como ano representativo de ventos.

Persp. Online: exatas \& eng., Campos dos Goytacazes, 20 (08) 25-42 - 2018 
Tabela 1. Desvio padrão médio anual

\begin{tabular}{ll}
\hline Ano & Desvio padrão médio \\
\hline 2004 & 0,0099 \\
2005 & 0,0111 \\
2006 & 0,0097 \\
2007 & 0,0190 \\
2008 & 0,0089 \\
2009 & 0,0165 \\
2010 & 0,0110 \\
\hline
\end{tabular}

A Figura 9 ilustra as rosas de ventos construídas para o ano representativo (2008) e para toda série temporal (2004 a 2010). Durante toda série temporal (2004 a 2010), constatou-se que as maiores ocorrências foram de ventos NE, com intensidades entre 3,1 a $6 \mathrm{~m} / \mathrm{s}$ (4,92\%), seguidos de ventos ENE, com intensidades entre 6,1 e $9 \mathrm{~m} / \mathrm{s}(4,50 \%)$. Observa-se ainda, bastante ocorrência de ventos de NNE, com intensidades entre 3,1 a $6 \mathrm{~m} / \mathrm{s}(4,10 \%)$. Durante o ano representativo (2008) verifica-se um comportamento similar à série de 2004 a 2010, com maiores ocorrências de ventos de ENE, com intensidades entre 6,1 e $9 \mathrm{~m} / \mathrm{s}(5,65 \%)$, de $\mathrm{NE}$, com intensidades entre 3,1 a $6 \mathrm{~m} / \mathrm{s}(4,85 \%)$, e de ENE com intensidades entre 9,1 e $12 \mathrm{~m} / \mathrm{s}(4,66 \%)$.
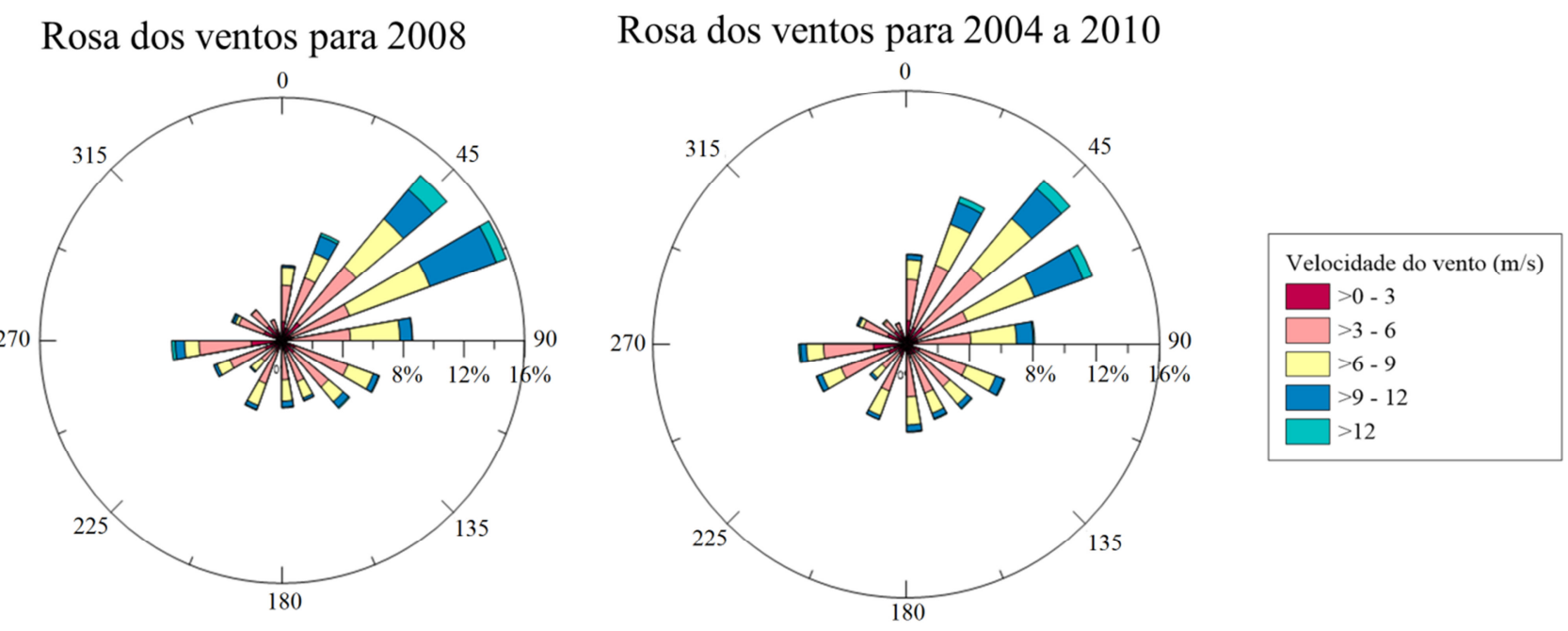

Figura 9: Rosas dos ventos para o ano representativo (2008) e para a série temporal (2004 a 2010) de acordo com dados medidos na estação meteorológica da Praticagem da Barra do Rio Grande

Através de uma análise detalhada sobre os dados de ventos de toda série temporal (2004 a 2010) (Figura 10), constatou-se que, durante o verão, as maiores frequências de ventos foram de $\mathrm{NE}$, com intensidades entre 6,1 e $9 \mathrm{~m} / \mathrm{s}(6,12 \%)$, de ENE, com intensidades entre 6,1 e $9 \mathrm{~m} / \mathrm{s}(6,11 \%)$ e de NE, com intensidades entre 3,1 e $6 \mathrm{~m} / \mathrm{s}(5,74 \%)$. De maneira muito semelhante, durante a primavera, as maiores ocorrências foram de ventos ENE (6,38\%), com intensidades entre 6,1 e $9 \mathrm{~m} / \mathrm{s}$, seguidos de ventos de NE $(5,30 \%)$, também com intensidades entre 6,1 e $9 \mathrm{~m} / \mathrm{s}$. Verifica-se também que houve bastante ocorrência de 
ventos provenientes de NE, mas com intensidades entre 3,1 e $6 \mathrm{~m} / \mathrm{s}(4,86 \%)$. Durante outono e inverno, as maiores frequências de ventos ainda foram de NNE e NE, mas com significativo aumento de ventos de $\mathrm{W}$ e WSW. Tanto no outono, quanto no inverno, as maiores frequências ocorreram com intensidades de ventos entre 3,1 e $6 \mathrm{~m} / \mathrm{s}$, nas direções NNE (5,25\% no outono e 5,42\% no inverno), W (5,04\% no outono e 4,42\% no inverno), WSW (4,92\% no outono e $4,36 \%$ no inverno).

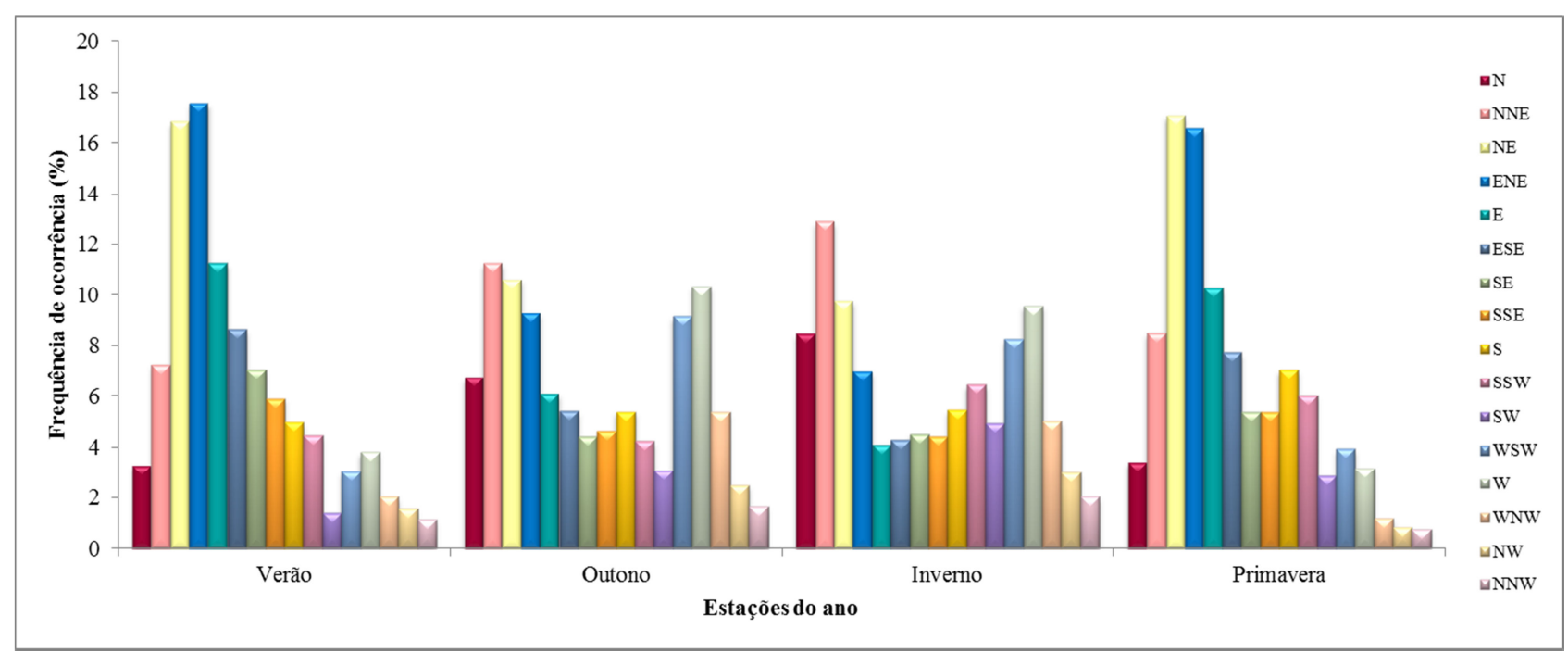

Figura 10: Histograma de direções de ventos atuantes nas estações do ano, conforme dados coletados na Praticagem da Barra do Rio Grande, durante o período de 2004 a 2010

De maneira geral, os resultados de ventos característicos da região, mostraram-se semelhantes a estudos realizados por diversos autores. Segundo Möller et al. (2001) as direções predominantes de ventos coincidem com a direção do eixo longitudinal do corpo lagunar (NE-SW). Malaval (1923, apud Calliari e Fachin, 1993) realizou um estudo sobre ventos durante o período de 1913 a 1915, observando que os ventos de NE foram os mais frequentes, seguidos de ENE, de SE e de SW. Toldo et al. (2006) concluíram que, durante o verão e a primavera de 1988, os ventos predominantes na margem oeste da Lagoa dos Patos foram de NE, enquanto que, durante outono e inverno, os ventos mais frequentes na margem leste eram provenientes de NW e SW. Segundo Möller (1996) o regime de ventos predominantes na região é de NE, associado ao anticiclone sobre o Oceano Atlântico. No inverno, devido à passagem de sistemas frontais, ocorre um aumento na frequência de ventos do quadrante sul. De acordo com Calliari e Fachin (1993) a alteração entre os anticiclones do Atlântico Sul e Polar durante o ano resulta na maior frequência de ventos do quadrante NE entre setembro e fevereiro, e do quadrante SW entre abril e agosto.

\subsection{Geração de ondas na Lagoa dos Patos através do modelo SWAN}

Através da geração e propagação de ondas em toda a Lagoa dos Patos, simuladas no SWAN a partir da série temporal de dados de intensidades e direções de ventos atuantes no ano de 2008, obtiveram-se os parâmetros de ondas para quatro pontos (A, B, C e D) situados nas proximidades de São Lourenço do Sul, conforme ilustrado na Figura 7. Os resultados são apresentados na Figura 11, onde se constata que os valores de alturas significativas do ponto A são maiores, devido à profundidade deste ponto ser maior. 

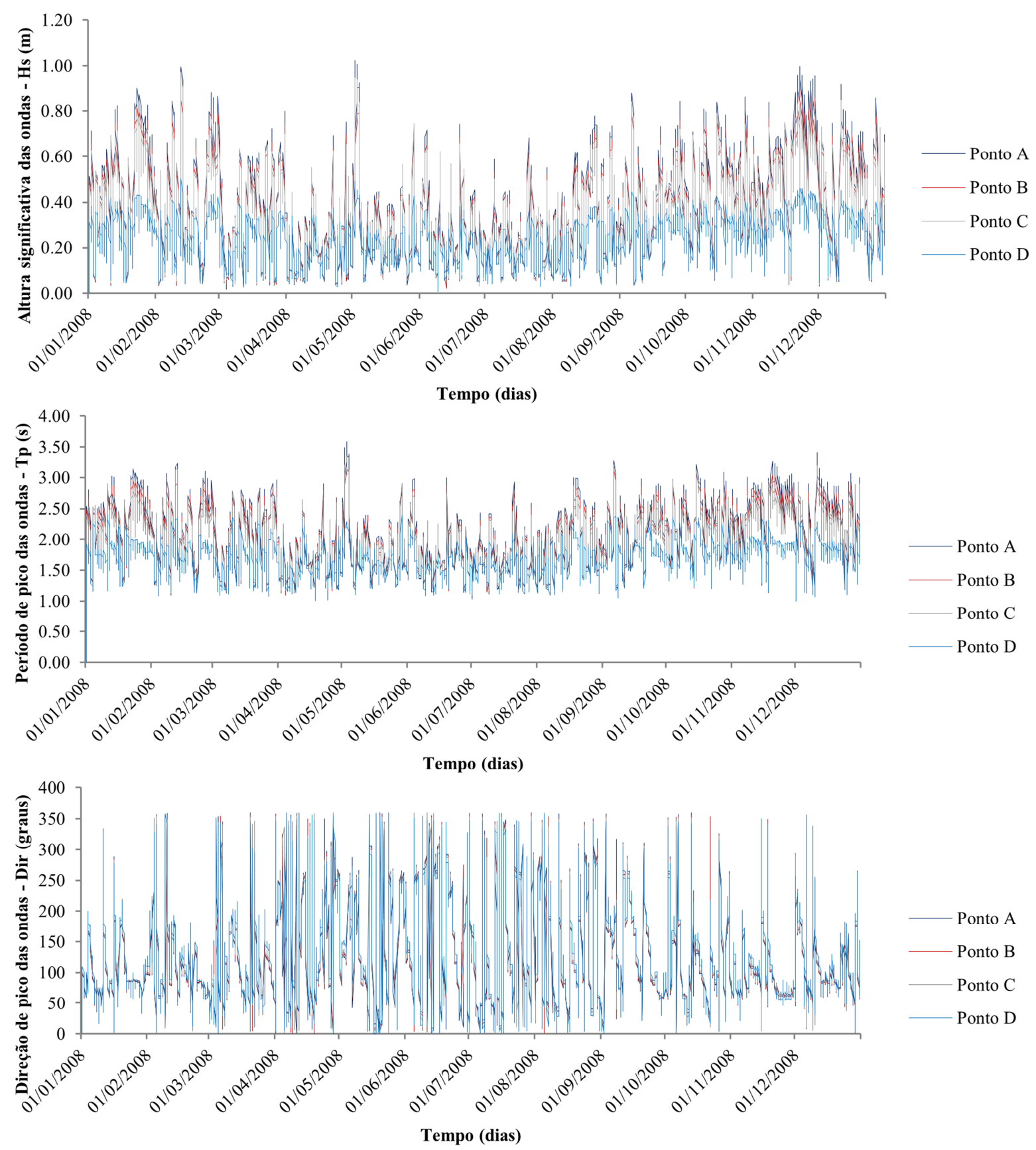

Figura 11: Alturas significativas, períodos de pico e direções de pico das ondas versus tempo para os 4 pontos (A, B, C e D) localizados no contorno da grade local (01 de janeiro a 31 de dezembro de 2008)

A seleção dos cenários representativos de ondas foi feita com base nos parâmetros de ondas do local que apresentou condições de maiores energias, no caso, o ponto A. Os parâmetros de ondas obtidos no ponto A foram corrigidos com os respectivos fatores de ajuste, conforme metodologia desenvolvida por Melo et al. (2010), que consiste em eliminar a tendenciosidade do modelo ao considerar que o viés deva ser igual a zero. No presente estudo, verificou-se a tendência do modelo em subestimar os valores medidos pelo ondógrafo, tanto para Hs quanto para Tp e Dp. Portanto, visando eliminar o viés ou tendenciosidade do modelo na previsão dos parâmetros (Hs, Tp e Dp), foram determinados os fatores de ajuste para cada variável, os quais são 1,14 para altura significativa, 1,36 para período de pico e 1,39 para direção de pico das ondas, conforme Lemke et al. (2015). 
Após a correção dos parâmetros de ondas (Hs, Tp e Dp) através dos correspondentes fatores de ajuste, aplicou-se a metodologia desenvolvida por Dobrochinski (2009), que consiste em reduzir o número de casos de ondas em cenários representativos. Na Figura 12 são ilustrados todos os casos de ondas obtidos através do SWAN e corrigidos através dos fatores de ajuste, para o ponto A, durante 2008, de acordo com as estações do ano. Os pontos em azul correspondem a todos os casos de ondas, já os pontos em vermelho representam os cenários característicos de ondas obtidos para cada classe. Na Tabela 2 são apresentados os cenários de ondas representativos de cada classe, com os valores de altura significativa, período de pico e direção de pico, de acordo com o número de ocorrência durante o ano (representado em dias).

Verão

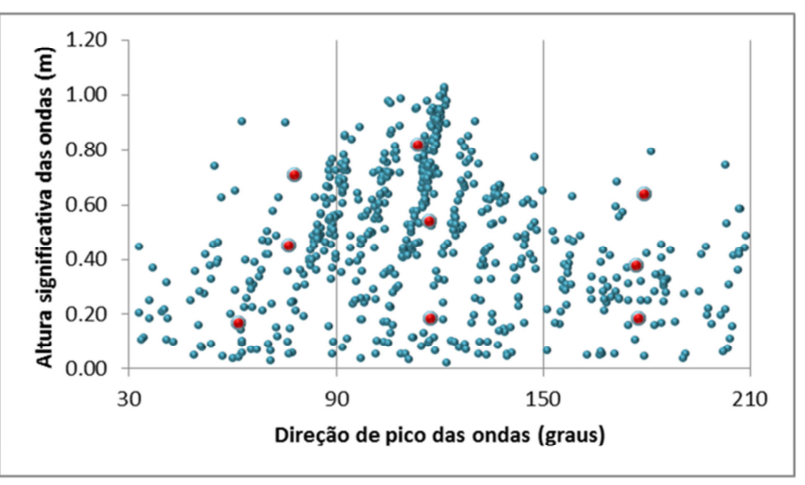

Inverno

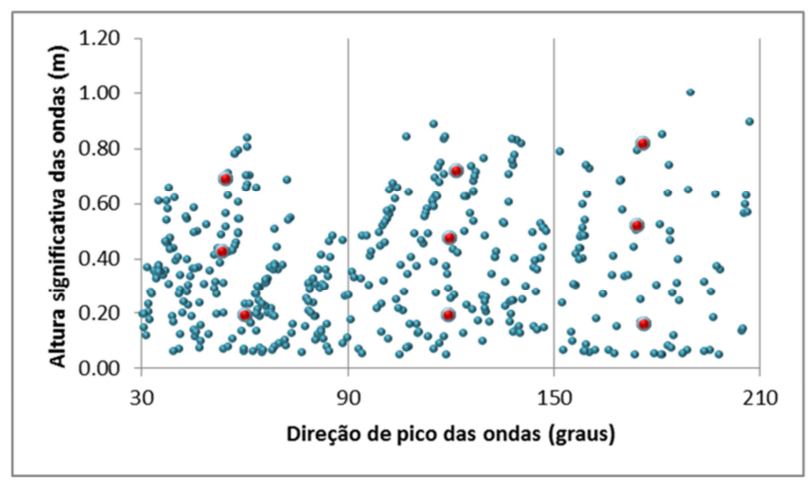

Outono

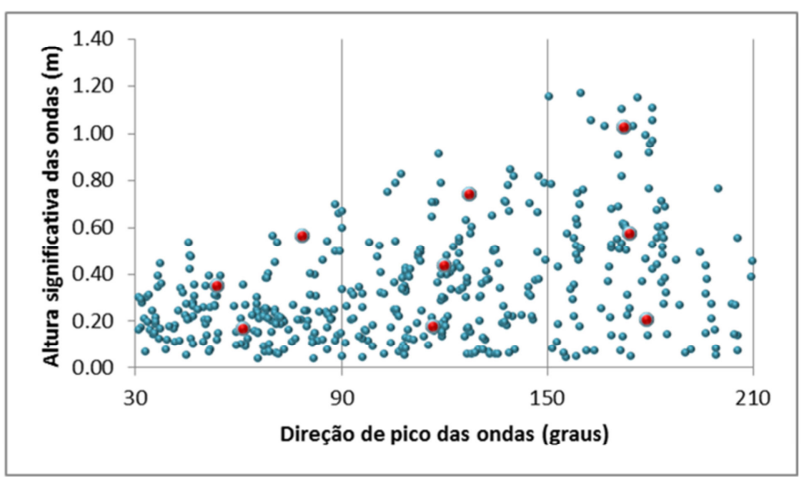

Primavera

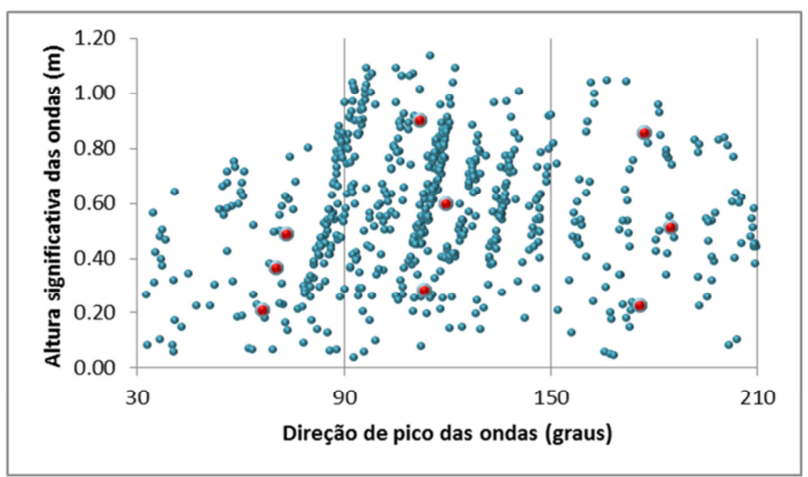

Figura 12: Casos de ondas para o verão, outono, inverno e primavera (os pontos em azul representam todos os casos de ondas referentes ao ponto A, obtidos através do SWAN e corrigidos pelos fatores de ajuste, e os pontos em vermelho representam cenários de ondas representativos de cada classe)

De maneira geral, constata-se que os cenários representativos de ondas correspondem a condições de um ambiente de baixa energia, onde o máximo valor de altura significativa é da ordem de 1 metro, e os valores de períodos de pico são todos menores que 5 segundos. O cenário de ondas com os maiores valores de altura significativa (1,03 metros) e período de pico (4,54 segundos) é característico do outono, com direção de pico de $172,4^{\circ}$ e duração de 1,88 dias. O caso de maior frequência ocorre na primavera, cenário 26 (altura significativa de 0,60 metros, período de pico de 3,39 segundos, direção de pico de $119,7^{\circ}$ ), com duração de cerca de 27 dias. O segundo caso de maior frequência ocorre durante cerca de 19 dias no verão, cenário 5 (altura significativa de 0,54 metros, período de pico de 3,24 segundos, direção de pico de $116,8^{\circ}$ ), apresentando características muito semelhantes ao cenário 26 da primavera. Ambos os cenários 5 e 26 estão associados a ventos de ENE com intensidades de $7,5 \mathrm{~m} / \mathrm{s}$ e $8,3 \mathrm{~m} / \mathrm{s}$, respectivamente, evidenciando a refração das ondas através da modelagem numérica.

Os valores médios de altura significativa ( 0,48 metros) e de período de pico ( 3 segundos) dos 36 cenários representativos encontrados neste estudo são muito próximos aos valores encontrados por Simão (2016) no estudo do padrão de ondas na Lagoa dos Patos através do modelo SWAN. O referido autor reconstituiu o padrão de ondas na laguna a partir de 30 anos de dados de ventos (1982 a 1912), obtendo 
resultados em um ponto localizado a cerca de $6 \mathrm{~km}$ da costa de São Lourenço do Sul, onde a profundidade local é de 3 metros. Simão (2016) constatou que as maiores frequências, neste local, foram de ondas com alturas significativas de até 0,4 metros e com períodos de pico de até 2,5 segundos. Embora a localização do ponto de análise de Simão (2016) não seja exatamente a mesma do ponto analisado neste estudo, os resultados são muito semelhantes.

Tabela 2. Cenários de ondas selecionados a partir do método das classes fixadas

\begin{tabular}{|c|c|c|c|c|c|c|c|c|c|c|c|}
\hline Cenário & $\begin{array}{c}\text { Estação } \\
\text { do ano }\end{array}$ & $\begin{array}{c}\text { Hs } \\
(\mathrm{m})\end{array}$ & $\begin{array}{l}\text { Tp } \\
\text { (s) }\end{array}$ & $\begin{array}{c}\text { Dp } \\
\text { (graus) }\end{array}$ & Dias & Cenário & $\begin{array}{c}\text { Estação } \\
\text { do ano }\end{array}$ & $\begin{array}{l}\text { Hs } \\
(\mathbf{m})\end{array}$ & $\begin{array}{l}\text { Tp } \\
\text { (s) }\end{array}$ & $\begin{array}{c}\text { Dp } \\
\text { (graus) }\end{array}$ & Dias \\
\hline 1 & & 0,17 & 2,04 & 61,66 & 7,25 & 19 & & 0,19 & 2,13 & 60,10 & 13,50 \\
\hline 2 & & 0,45 & 2,87 & 76,38 & 7,50 & 20 & & 0,43 & 2,76 & 53,42 & 8,63 \\
\hline 3 & & 0,71 & 3,36 & 78,01 & 1,88 & 21 & & 0,69 & 3,27 & 54,38 & 2,38 \\
\hline 4 & & 0,18 & 2,16 & 117,5 & 10,13 & 22 & & 0,19 & 2,16 & 119,3 & 7,88 \\
\hline 5 & Verão & 0,54 & 3,24 & 116,8 & 19,13 & 23 & Inverno & 0,48 & 3,08 & 119,5 & 7,00 \\
\hline 6 & & 0,82 & 3,80 & 113,7 & 15,26 & 24 & & 0,72 & 3,68 & 121,6 & 4,13 \\
\hline 7 & & 0,18 & 2,21 & 177,6 & 6,00 & 25 & & 0,16 & 2,13 & 176,2 & 5,38 \\
\hline 8 & & 0,38 & 2,89 & 177,0 & 6,25 & 26 & & 0,52 & 3,33 & 174,3 & 3,88 \\
\hline 9 & & 0,64 & 3,65 & 179,4 & 1,25 & 27 & & 0,82 & 4,07 & 175,9 & 1,00 \\
\hline 10 & & 0,17 & 2,05 & 61,2 & 14,00 & 28 & & 0,21 & 2,18 & 66,2 & 5,75 \\
\hline 11 & & 0,35 & 2,54 & 53,8 & 5,00 & 29 & & 0,49 & 2,94 & 73,1 & 7,38 \\
\hline 12 & & 0,57 & 3,13 & 78,4 & 1,00 & 30 & & 0,73 & 3,42 & 76,9 & 4,50 \\
\hline 13 & & 0,18 & 2,12 & 116,7 & 11,13 & 31 & & 0,28 & 2,48 & 113,2 & 7,50 \\
\hline 14 & Outono & 0,43 & 2,99 & 119,9 & 7,25 & 32 & Primavera & 0,60 & 3,39 & 119,7 & 26,76 \\
\hline 15 & & 0,74 & 3,75 & 127,4 & 2,63 & 33 & & 0,90 & 3,93 & 111,8 & 12,13 \\
\hline 16 & & 0,21 & 2,27 & 179,0 & 6,00 & 34 & & 0,22 & 2,35 & 175,9 & 3,25 \\
\hline 17 & & 0,57 & 3,46 & 174,0 & 5,88 & 35 & & 0,51 & 3,28 & 184,7 & 6,13 \\
\hline 18 & & 1,03 & 4,54 & 172,4 & 1,88 & 36 & & 0,86 & 4,14 & 177,3 & 3,38 \\
\hline
\end{tabular}




\section{CONCLUSÕES}

Este estudo permitiu estimar 36 cenários de ondas característicos da enseada de São Lourenço do Sul (Lagoa dos Patos) através do modelo SWAN, o qual foi previamente aferido com parâmetros de ondas medidos pelo primeiro ondógrafo direcional fundeado no corpo lagunar. Até o presente momento, não há conhecimento de outros estudos com aplicação de modelos de geração e propagação de ondas no corpo principal da Lagoa dos Patos que tenham sido ajustados a partir de dados de ondas medidos por meio de equipamentos específicos. Desta forma, os parâmetros de ondas obtidos pelo ondógrafo na Lagoa dos Patos em 2015 representam um grande avanço para a construção da caracterização do regime de ondas neste ambiente, pois além de consistirem em dados inéditos medidos no corpo lagunar, constituem uma base real para aferição de modelos numéricos de geração e propagação de ondas.

O modelo SWAN consistiu em uma ferramenta indispensável para a construção do regime ondulatório na região de estudo, gerado a partir de dados de intensidades e direções de ventos do ano representativo (2008). O método para selecionar os cenários de ondas mostrou-se eficaz, visto que 2928 casos foram representados dentro de 36 classes, obtendo-se cenários característicos de ondas com valores de alturas significativas entre $0,16 \mathrm{~m}$ e $1,03 \mathrm{~m}$, com períodos de pico entre $2,05 \mathrm{~s} \mathrm{e} 4,54 \mathrm{~s}$, e com direções de pico entre $30^{\circ}$ e $210^{\circ}$. A metodologia apresentada foi aplicada a uma específica região de estudo, mas pode ser utilizada em outras regiões.

Este trabalho apresenta elevada importância para pesquisas científicas que visam caracterizar o regime de ondas na Lagoa dos Patos, assim como para estudos que objetivam determinar o transporte sedimentar na enseada de São Lourenço do Sul. Estes 36 cenários característicos de ondas foram posteriormente utilizados como forçantes de um modelo morfológico para a região de estudo, de modo a quantificar o transporte de sedimentos, e com isso avaliar propostas de obras de proteção costeira para a foz do Arroio Carahá, tudo conforme Lemke (2015).

\section{REFERÊNCIAS}

AGUIAR, D. F. Metodologia para determinação da onda de projeto baseada em dados do WW3: aplicação aos molhes do Rio Grande. 2014. Dissertação (Mestrado em Engenharia Oceânica) - Universidade Federal do Rio Grande, Rio Grande, 2014.

CALLIARI, L. J. \& FACHIN, S. Laguna dos Patos: Influência nos Depósitos Lamíticos Costeiros. Pesquisas em Geociências, Porto Alegre, v. 20, p. 57-69, 1993.

DIRETORIA DE HIDROGRAFIA E NAVEGAÇÃO DA MARINHA DO BRASIL. Página eletrônica. Disponível em: <http://www.mar.mil.br/dhn/chm/box-cartas-raster/raster_disponiveis.html>.

DOBROCHINSKI, J. P. H. Redução e Esquematização de Clima de Ondas para Modelagem Mordológica. 2009. Trabalho de Conclusão de Curso de Oceanografia. Universidade do Vale do Itajaí, Itajaí, 2009.

FISCHER, A. \& CALLIARI, L. J. Variações Morfodinâmicas das Praias do "Saco do Laranjal", Costa Noroeste do Estuário da Laguna dos Patos, RS. Pesquisas em Geociências, Porto Alegre, v. 38, n. 3, p. 283296, 2011.

FONTOURA, J. A. S. Hidrodinâmica Costeira e Quantificação do Transporte Longitudinal de Sedimentos Não Coesivos na Zona de Surfe das Praias Adjacentes aos Molhes da Barra do Rio Grande, RS, Brasil. (Aplicação às praias do Cassino, Mar Grosso e adjacências dos Molhes Leste e Oeste da embocadura do estuário da Lagos dos Patos). 2004. Tese (Doutorado em Recursos Hídricos e Saneamento Ambiental) Universidade Federal do Rio Grande do Sul, Porto Alegre, 2004.

FONTOURA, J. A. S.; NICOLODI, J. L.; ROMEU, M. A. R.; Filho, E. M.; LEMKE, N.; AGUIAR, D. F. \&

Persp. Online: exatas \& eng., Campos dos Goytacazes, 20 (08) 25-42 - 2018

seer.perspectivasonline.com.br 
GOULART, M. M. Medição direcional de ondas na Lagoa dos Patos, RS, Brasil. In: CONGRESSO HIDROVIÁRIO DA SOCIEDADE BRASILEIRA DE ENGENHARIA NAVAL (SOBENA), 2015, Manaus. Anais... Manaus, 2015.

LALBEHARRY, R. Evaluation of the CMC Regional Wave Forecasting System against Buoy Data. Atmosphere-Ocean, v. 40, p. 1-20, 2001.

LEMKE, N. Morfodinâmica da Embocadura do Arroio Carahá, Lagoa dos Patos, São Lourenço do Sul - RS. 2015. 346 f. Tese (Doutorado em Oceanografia Física, Química e Geológica) - Universidade Federal do Rio Grande, Rio Grande, 2015.

LEMKE, N.; FONTOURA, J. A. S.; CALliARI, L. J.; AGUIAR, D. F.; MELO, E.; NICOLODI, J. L.; ROMEU, M. \& GOULART, M. M. Estudo comparativo entre modelagem e medições de ondas na Lagoa dos Patos - RS, Brasil. In: SIMPÓSIO SOBRE ONDAS, MARÉS, ENGENHARIA OCEÂNICA E OCEANOGRAFIA POR SATÉLITE, 11., 2015, Arraial do Cabo. Anais Eletrônicos... Arraial do Cabo, 2015. Disponível em: <http://media.wix.com/ugd/f9878c_29ebe79678074b92bcb495f7beeb39d1.pdf $>$. Acesso em: 14 jan. 2015.

LIN, W.Q., SANFORD, L.P. \& SUTTLES, S.E. Wave measurement and modeling in Chesapeake bay. Continental Shelf Research, v. 22, p. 18-19, 2002.

MACHADO, M. D. Um Estudo sobre o Clima de Ondas e o Transporte de Lama ao Largo da Praia do Cassino, RS. 2013. 346 f. Tese (Doutorado em Engenharia Oceânica) - Universidade Federal do Rio de Janeiro, Rio de Janeiro, 2013.

MELO, E.F., HAMMES, G.R., FRANCO, D., \& ROMEU, A.R. Aferição de desempenho do modelo WW3 em Santa Catarina. In: SEMINÁRIO E WORKSHOP EM ENGENHARIA OCEÂNICA (SEMENGO), 3, 2008, Rio Grande, Anais... Rio Grande, 2008.

MELO, E.F., ROMEU, M. A.R. \& HAMMES, G.R. Condições Extremas de Agitação Marítima ao Largo de Rio Grande a partir do Modelo WW3. Seminário e Workshop em Engenharia Oceânica (SEMENGO), 4, 2010, Rio Grande, Anais... Rio Grande, 2010.

MOEINI, M. H. \& ETEMAD-SHAHIDI, A. Wave Parameter Hindcasting in a Lake Using the SWAN Model. Scientia Iranica. Sharif University of Technology. Transaction A: Civil Engineering, v. 16, n. 2, p. 156-164, 2009.

MÖLLER JR., O. O.; CASTAING, P., SALOMON, J.C. \& LAZURE, P. The influence of local and nonlocal forcing effects on the subtidal circulation of Patos Lagoon. Estuaries, v. 24, n. 2, p. 297-311, 2001.

MÖLlER Jr., O. O.; LORENZZETTI, L. A.; STECH, J.; MATA, M. M. The Patos Lagoon Summertime Circulation and Dynamics. Continental Shelf Research, v. 16, n. 3, p. 335-351, 1996.

NICOLODI, J. L. O padrão de ondas no Lago Guaíba e sua influência nos processos de sedimentação. 2007. 178 f. Tese (Doutorado em Geociências) - Universidade Federal do Rio Grande do Sul, Rio Grande do Sul, 2007.

NICOLODI, J. L.; TOLDO JUNIOR, E. E.; FARINA, L. Dynamic and resuspension by waves and sedimentation pattern definition in low energy environments. Guaíba Lake (Brazil). Brazilian Journal of Oceanography, São Paulo, v. 61, n. 1, p. 55-64. 2013.

REDE DE MONITORAMENTO DE ONDAS EM ÁGUAS RASAS. Página eletrônica. Disponível em: $<\mathrm{http}: / /$ www.redeondas.furg.br/index.php/pt/>.

ROMEU, M. A. R.; FONTOURA, J. A. S.; MELO, E.; HAMMES, G. Estimativa dos Cenários Característicos de Agitação Marítima para a Região Oceânica do RS Utilizando Dados de Reanálise do

Persp. Online: exatas \& eng., Campos dos Goytacazes, 20 (08) 25-42 - 2018

seer.perspectivasonline.com.br 
Modelo WW3. In: Seminário e Workshop em Engenharia Oceânica (SEMENGO), 4, 2010. Rio Grande, Anais... Rio Grande, 2010.

SIMÃO, C. E. Estudo do Padrão de Ondulações na Lagoa dos Patos utilizando o modelo SWAN (DELFT3D), RS, Brasil. 2016. Dissertação (Mestrado em Engenharia Oceânica) - Universidade Federal do Rio Grande, Rio Grande, 2016.

TOLDO, E. E. Jr., ALMEIDA, L. E. S. B.; CORRÊA, I. C. S.; FERREIRA, E. R.; GRUBER, N. L. S. Wave Prediction Along Lagoa dos Patos Coastline, Southern Brazil. Revista Atlântica, v. 28, n. 2, p. 87-95, 2006.

U. S. ARMY CORPS OF ENGINEERS, 1984. Shore Protection Manual. Coastal Engineering Research Center. Washington, DC: US Government Printing Office, 597p, 1984.

VAN GRUIJTHUIJSEN, M.F.J. Validation of the wave prediction model SWAN using field data from Lake George, Australia. 1996. Tese de Doutorado - Delft University of Technology, Holanda, 1996. 